\title{
Diálogo entre feminismos en el contexto de la globalización neoliberal
}

Dialogue between Feminisms on the Context of Neoliberal Globalization

Elsa Ivette Jiménez Valdez' (iD 0000-0002-9440-5142

'Benemérita Universidad Autónoma de Puebla, Doctorado en Economía Política del Desarrollo, Puebla, Puebla, Mexico.72000-depd@correo.buap.mx

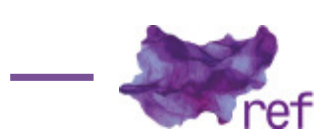

TAPIA GONZÁLEZ, Aimé.

Mujeres indígenas en defensa de la Tierra.

Madrid: Ediciones Cátedra, 2018.

¿Cuáles son las características del feminismo latinoamericano? ¿Cómo se relaciona con otros feminismos occidentales y con los feminismos del Sur? ¿Existe un pensamiento feminista de la sostenibilidad en comunidades indígenas? ¿Qué aporta el multiculturalismo a la lucha por los derechos de las mujeres? Estas preguntas son algunos de los cuestionamientos que aborda y a los que busca dar respuesta Aimé Tapia en su libro Mujeres indígenas en defensa de la tierra.

Con esta obra la autora, doctora en Filosofía por la Universidad de Valladolid/Salamancas y profesora de la Universidad de Colima, se lanza a la tarea de tender puentes entre el feminismo occidental de orígenes ilustrados y los feminismos indígenas latinoamericanas. Reconociendo a los primeros como herederos de los principios de autonomía, libertad e igualdad y a los segundos como portadores de una episteme no occidental que se fundamenta en la comunidad, en el respeto a la igual dignidad de todos los seres vivos y en los valores de reciprocidad $e$ interdependencia. Para la autora, ambos posicionamientos son imprescindibles para encarar los retos de la actual crisis ecológica y económica global. El problema radica en cómo acercarlos.

Aimé Tapia argumenta que las voces de las mujeres indígenas que defienden la Tierra y el territorio son esenciales para procurar el acercamiento entre diversos feminismos al ser portadoras de éticas, epistemologías y prácticas políticas que nacen de su lucha por la sobrevivencia. Lejos de todo victimismo, estas mujeres emergen como sujetos políticos que, en cruce de múltiples violencias y exclusiones, ofrecen claves imprescindibles para tejer alternativas ante el ecocidio causado por el capitalismo globalizado.

Mujeres indígenas en defensa de la tierra se estructura en cuatro capítulos. En el primero, la autora traza los principales referentes de la filosofía de los pueblos del Abya Yala. Tapia identifica que esta epistemología concibe el conocimiento como un diálogo respetuoso en el que participan el conjunto de seres humanos y el resto de seres vivos, teniendo en común una corporalidad vulnerable y necesitada - e igual dignidad. Desde esta visión se aspira a una convivencia armónica que acoja la diversidad en el marco de relaciones complementarias, recíprocas y de interdependencia. El eje central de esta visión es la concepción nosótrica, que se fundamenta en la comunidad. Entendida ésta no como una suma de individuos, sino como un ámbito que se alimenta de acciones individuales y colectivas en las que participan todos los seres vivos y la Tierra.

La autora, sin embargo, previene tanto de la tentación de romantizar las culturas, como de rechazarlas en bloque. Así, reconoce la falta de coherencia entre el principio nosótrico y el trato 
desigual que reciben las mujeres al interior de los pueblos indígenas. Inconsistencia que está siendo desafiada por las mujeres al interior de sus comunidades.

En el segundo capítulo, Tapia ofrece un panorama de la transformación liderada por las indígenas, caracterizada por su enfrentamiento a la matriz patriarcal, capitalista y racista. Lo feminismos indígenas enarbolan aspectos de sus propias culturas, como son la complementariedad y la reciprocidad, y se caracterizan por promover transformaciones comunitarias que involucran las relaciones entre mujeres y hombres, entre mujeres y mujeres, hombres y hombres y de los seres humanos con la naturaleza.

En consonancia con el Ejército Zapatista de Liberación Nacional (EZLN), estas mujeres afirman la capacidad de los pueblos indígenas para revisar críticamente sus tradiciones culturales. Defendiendo que los derechos étnicos no pueden concebirse desvinculados de los derechos de las mujeres y de la naturaleza.

El tercer capítulo presenta una sinfonía tejida a partir del pensamiento de feministas occidentales, feministas del Sur y feministas indígenas del Abya Yala para discutir la noción de multiculturalidad y distinguir los aportes de los feminismos del Sur y los Indígenas en la construcción de un nuevo universalismo. Este apartado ofrece un entramado de visiones que la autora concibe como un tapiz complejo, hilvanado a partir de "posturas difíciles de conciliar" (Aimé TAPIA GONZÁLEZ, 2018, p. 159).

Al terminar este recorrido, por demás rico y lleno de matices, Tapia confirma la posibilidad de establecer diálogos entre estas visiones, en el marco de una revisión auto/crítica que tenga como condición dar prioridad a las voces de mujeres indígenas e incluir sus demandas en las agendas feministas internacionales. Algunos aspectos centrales que la autora reconoce en los feminismos indígenas son: la confluencia de posturas críticas, la relevancia de las tareas de reproducción, la recuperación de categorías de impronta indígena, la relación entre los cuerpos y los territorios y la vinculación de éstos con la biodiversidad de la Tierra. Previamente, la autora habría señalado que la mayor fortaleza de los procesos organizativos indígenas la constituye su capacidad para construir lo común sin renunciar a la diversidad, aspecto central para procurar los acercamientos entre distintas concepciones feministas.

El cuarto capítulo presenta la historia de vida de María de Jesús Patricio, médica náhuatl y vocera del Consejo Nacional Indígena (CNI), así como las luchas de mujeres indígenas por su derecho y el de sus comunidades al agua en diversas localidades en México, en el Salvador y en Chile. La autora concluye que estas mujeres han desarrollado su feminismo en defensa de la Tierra y el territorio desde sus prácticas de resistencia. Forman parte de las luchas de mujeres pobres del Sur frente a un modelo de desarrollo en crisis. Desde estos contextos estas defensoras revelan un poder alternativo, fundado en el nosotros/as indígena. Con sus acciones develan nuevos horizontes éticos para pensar y caminar en la construcción de culturas plurales, ecológicamente sostenibles y democráticas que reconozcan las voces y miradas indígenas.

El acercamiento entre feminismos occidentales y del Abya Yala implica poner sobre la mesa debates conceptuales y teóricos de distintos niveles y coordenadas. A lo largo del libro, Aimé Tapia va trenzando múltiples hebras, articulando debates por demás relevantes. La autora cuestiona la capacidad de la filosofía para admitir otras formas de conocer, maneras de concebir el conocimiento y sujetos epistémicos; al tiempo que afirma la potencialidad de construir universales a partir de la recuperación de miradas múltiples y saberes contextualizados.

Frente a las críticas posmodernas y poscoloniales que denuncian que la Modernidad y el Occidente se han enarbolado como modelos dominantes de civilización universal, autoritarios y homogenizadores, Tapia defiende modos alternativos de concebir ambos proyectos. En su planteamiento, las luchas por la igualdad entre mujeres y varones al interior de los pueblos originarios pueden interpretarse como procesos crítico-reflexivos en el marco de un proyecto ilustrado que continúa en construcción.

En el fondo de estas controversias, la autora sitúa la pregunta sobre el multiculturalismo y sus alcances, pincelando claroscuros para escapar de posiciones monolíticas y polarizadas. El diálogo, la pluralidad y el acuerdo son ejes imprescindibles para lograr no sólo el encuentro entre los feminismos europeos y americanos, sino para ampliar la concepción filosófica del mundo. El reto está en la capacidad de establecer diálogos horizontales que sepan acoger diferentes miradas y perspectivas.

La autora se sitúa en el marco del ecofeminismo constructivista defendiendo que las mujeres están conectadas con el cuidado de la Tierra y el territorio desde sus experiencias cotidianas, asociadas a las tareas y roles de género. Se posiciona en contra de las perspectivas esencialistas que las encapsulan como madres o como seres más cercanos a la naturaleza, así como de aquellas que dejan caer sobre sus hombros la responsabilidad absoluta de los cuidados y de la preservación de la vida, en el marco de un proyecto de justicia global que redistribuya la propiedad, los recursos, el conocimiento y poder.

Para concluir esta síntesis, me parece importante reconocer en esta obra un mapa valioso que permite ubicar exponentes y movimientos indígenas, así como algunas de sus principales 
características. El planteamiento del libro ofrece coordenadas importantes para lograr un cercamiento entre feminismos diversos. El diálogo multicultural es esencial para proponer formas de enfrentar las crisis actuales que atraviesa la humanidad, localizadas en el entronque capitalistapatriarcal y racista. Por último, la autora deja abierta la veta a futuros trabajos e indagaciones. En este sentido, resultaría valioso profundizar en el diálogo de estas posturas con los feminismos decoloniales, críticos de los fundamentos mismos de la Modernidad y de la idea de Occidente.

\section{Referencia}

TAPIA GONZÁLEZ, Aimé. Mujeres indígenas en defensa de la Tierra. Madrid: Ediciones Cátedra, 2018.

Elsa Ivette Jiménez Valdez (elsa.jimenez@iberopuebla.mx) es doctorante en la Benemérita Universidad Autónoma de Puebla (BUAP). Maestra en Ciencias Sociales por el Colegio de Sonora; Maestra en Derechos Humanos y Paz por ITESO, Universidad Jesuita de Guadalajara; Especialización en Políticas Públicas y Justicia de Género por CLACSO.

\section{COMO CITAR ESSE ARTIEO DE ACORDO COM AS NORMAS DA REVISTA}

JIMÉNEZ VALDEZ, Elsa Ivette. "Diálogo entre feminismos en el contexto de la globalización neoliberal". Revista Estudos Feministas, Florianópolis, v. 28, n. 1, e66072, 2020.

\section{CONTRIBUIÇÃO DE AUTORIA}

Não se aplica.

FINANCIAMENTO

Não se aplica.

\section{CONSENTIMENTO DE USO DE IMAGEM}

Não se aplica.

\section{APROVAÇÃO DE COMITÊ DE ÉTICA EM PESQUISA}

Não se aplica.

\section{CONFLITO DE INTERESSES}

Não se aplica.

\section{LICENÇA DE USO}

Este artigo está licenciado sob a Licença Creative Commons CC-BY International. Com essa licença você pode compartilhar, adaptar, criar para qualquer fim, desde que atribua a autoria da obra.

HISTÓRICO 